\title{
Selvmordsrisiko blandt personer diagnosticeret med demens
}

\author{
Ved Annette Erlangsen
}

\begin{abstract}
Har personer med demens en højere selvmordsrisiko? - Eller påvirker sygdommen de kognitive færdigheder således at den virker beskyttende mod selvmord? Dette studie, som tidligere er blevet publiceret på engelsk (Erlangsen et al., 2008) undersøger om demens er forbundet med en forhøjet risiko for selvmord.
\end{abstract}

\section{Abstrakt}

Formål: Studiet undersøger risikoen for selvmord blandt personer med hospitalsdiagnosticeret demens og dets sammenhæng med depression.

Data og metode: Individbaserede registerdata dækkende alle personer fyldt 50 år og derover bosat i Danmark i perioden 1. januar 1990 til 31. december 2000 $(\mathrm{N}=2.474 .767)$ blev analyseret. Eventhistory analyseteknik blev benyttet til at beregne relative risiko for $\mathrm{d} \varnothing \mathrm{d}$ af selvmord i multivariable analyser.

Resultat: I alt 18.648.875 personår blev observeret over det 11-årige studieforl $\varnothing \mathrm{b}$. Der forekom 136 selvmord blandt personer med demens diagnosticeret ved hospitalsindlæggelse. Den relative risiko for selvmord blandt mænd og kvinder i alderen 50-69 år med demens var henholdsvis 8,5 [CI-95\%: 6,3-11,3] og 10,8 [CI-95\%:7,4-15,7]. Personer fyldt 70 år og derover med demensdiagnoser havde en tre gange højere selvmordsrisiko end personer uden demens. Den forhøjede selvmordsrisiko blandt personer med demens forblev signifikant også efter justering for depressionsdiagnoser. Henholdsvis $40 \%$ og $38 \%$ af selvmord blandt mænd og kvinder med demens fandt sted inden for det første år efter demensdiagnosen første gang blev konstateret.

Konklusion: Demens, defineret som diagnosticeret ved hospitalsindlæggelse, var forbundet med en højere selvmordsrisiko for personer fyldt 50 år og derover. Særligt tiden efter første diagnose og dobbeltdiagnose med depression korrelerede med en forh $\varnothing j e t$ risiko for selvmord.

\section{Engelsk abstrakt}

Objective: The current study aims to examine the risk of suicide in persons diagnosed with dementia during a hospitalization and its relationship to mood disorders.
Data and method: Individual-level register data on all persons aged $50+$ living in Denmark during January 1 , 1990 through December 31, 2000 (N $=2,474,767)$ were included in the analysis. Event-history analysis was applied to calculate relative risks of dying by suicide while controlling for select timevarying covariates

Results: A total of $18,648,875$ personyears were observed during the 11-year study period. During this period, 136 persons who previously were diagnosed with dementia died by suicide. Men and women aged 50-69 years with hospital presentations of dementia had a relative suicide risk of 8.5 [CI-95\%: 6.3-11.3] and 10.8 [CI-95\%:7.4-15.7], respecti-vely. Those who aged 70 or older with dementia had a threefold higher risk than persons with no dementia. The risk among persons with dementia remained significant when controlling for diag-noses of mood disorders. As many as $40 \%$ of the men and $38 \%$ of the women who died by suicide died within the first year after initial dementia diagnosis.

Conclusions: Dementia, determined during hospitalization, was associated with an elevated risk of suicide for older adults. Particularly, time shortly after initial diagnosis and presence of mood disorders was found to correlate with an increased risk of suicide.

\section{Introduktion}

Ældre lever længere nu om dage end tidligere generationers ældre. Særligt de ældste ældres livslængde er blevet forøget over de seneste årtier, og det er den aldersgrupper som forventes at vokse mest i dette århundrede er de allerældste.

Nutidens ældre er fysisk mere velfungerende end tidligere generationers, men de unddrager sig dog ikke visse sygdomme, der især hører alderdommen til. Et eksempel på dette er demens. Det vurderes at i de udviklede lande har 1,3\%-1,9\% af personer i aldersgruppen 65-69 år demens, mens prævalensen er mellem 22\%-33\% blandt de ældste ældre fyldt 85 år og derover (Ferri et al., 2005). Når flere ældre lever til de ældste aldersgrupper, betyder dette også flere ældre med demens samt hvad det bringer af behov for behandling og pleje. Vor viden omkring selvmord og demens har hidtil været meget begrænset og bestod hovedsaglig af rapporter om enkelte demente patienter med suicidal adfærd samt kliniske studier om psykiatrisk indlagte patienter med demens. $\mathrm{Vi}$ vidste f.eks. ikke om personer med demens i den generelle befolkning havde en højere eller lavere selvmordsrate. Resultaterne fra kliniske studier tydede på at demens virkede forebyggende overfor selvmord (Harris \& Barraclough, 1997; Erlangsen et al., 2006; Conwell, 1995). Disse fund st $\varnothing$ ttede hypotesen om at nedsatte kognitive færdigheder, der kendetegner de senere stadier af demens, muligvis forhindrede patienter $i$ at udføre komplekse handlinger som et selvmord.

Vi ved fra andre studier at selvmordsraten varierer med alderen - også blandt forskellige aldersgrupper af ældre (Erlangsen et al., 2003). Vi ved også at depression er forbundet med en højere selvmordsrisiko blandt ældre generelt (Conwell \& Thompson, 2008), men det er uklart hvordan dette relaterer til personer med demens. Det er påvist at stressfyldte hændelser påvirker selvmordsrisikoen (Paykel, 1976), så det er muligt, at det at blive diagnosticeret med demens påvirker individets risiko for selvmord, men det er endnu ikke unders $\varnothing g t$.

Formålet med vores studie var at undersøge om personer diagnosticeret med demens havde en højere eller lavere selvmordsrisiko end den generelle befolkningen samt at identificere prædiktorer for selvmord blandt demente. 


\section{Data og metode}

Individ-baserede registeroplysninger over hele befolkningen fyldt 50 år og derover bosat i Danmark i perioden 1990-2000 blev benyttet til analyserne. Personlige og socio-demografiske data blev samk $\varnothing \mathrm{rt}$ med oplysninger om psykiatriske (siden 1972) og somatiske (siden 1985) hospitalsindlæggelser fra henholdsvis Det psykiatrisk Centralregister og Landspatientregisteret (Munk-Jørgensen \& Mortensen, 1997; Mosbech et al., 1995).

Oplysninger om udkommet, $\mathrm{d} \varnothing \mathrm{d}$ af selvmord, stammer fra D $\varnothing$ dsårsagsregisteret, hvor d $\varnothing$ dsårsagen i den unders $\varnothing$ gte periode blev registreret ifølge den 8. og 10. revision af Den internationale klassifikation af sygdomme og Dødsårsager (ICD).

Alle personer som blev diagnosticeret med demens (hoved- eller bidiagnose) under en psykiatrisk eller somatisk hospitalsindlæggelse blev fra denne dato betragtet som værende demente. Historiske oplysninger om indlæggelser før observationsperiodens begyndelse blev inddraget for at identificere personer, der var blevet diagnosticeret med demens før 1990. Kun hospitalsdiagnoser af demens blev inkluderet, i Danmark finder der desværre ikke registeroplysninger om diagnoser stillet af praktiserende læge. Standard ICD-koder blev benyttet til at identificere diagnoser dækkende demens og depression. Fra den dato, hvor diagnosen depression blev stillet første gang, blev individet ligeledes betragtet som havende en depression.

Studiet bestod af et komplet kohortestudie indeholdende alle personer bosat i Danmark i den unders $\varnothing$ gte periode. Alle personer fyldt 50 år og derover blev inkluderet, uafhængig af personens kognitive færdigheder, institutionalisering eller hospitalsindlæggelser.

Overlevelsesanalyse (event-history analyse) blev benyttet til at beregne relative risiko for selvmord, mens der i de multivariate analyser blev kontrolleret for følgende tidsvarierende variable: kalenderår, alder, ægteskabelig status, samboende status og somatisk comorbiditet. Den statistiske metode gjorde det muligt at tage højde for ændringer undervejs i studieforl $\varnothing$ bet f.eks. i diagnoser; en person bliver betragtet som havende demens, depression eller begge diagnoser fra den dato hvor diagnosen første gang konstaters under en hospitalsindlæggelse. Den relative risiko betegner, i vores tilfælde, sandsynligheden for at en person med demens begår selvmord sammenholdt med sandsynligheden for selvmord i den generelle del af befolkningen. Exponeringstiden beregnes i personår, dvs. antal dage en person tilbringer i studiepopulationen omregnet til år. Vi beregnede 95\% konfidensintervaller for at identificere om statistiske associationer var signifikante, dvs. ikke var forårsaget af tilfældige korrelationer.

Projektet blev godkendt af det danske Datatilsynet.

\section{Resultater}

Over 2,4 mill. individer fyldt 50 år og derover blev observerede i 18,6 mill. personår, hvoraf ca. 0,5\% af observationstiden dækkede personer diagnosticeret med demens. I løbet af de 11 års studieforl $\varnothing b$ forekom der i alt 136 selvmord blandt personer diagnosticeret med demens, fordelt på 80 selvmord bland mænd og 56 blandt kvinder.

\section{Selvmordsrate blandt demente}

Den gennemsnitlige selvmordsrate mænd fyldt 50 år og derover med demens, var 229 per 100.000 person-år mod 42 selvmord per 100.000 for den generelle befolkning. Den gennemsnitlige selvmordsrate for kvinder diagnosticeret med demens var 107 per 100.000 mens den kvindelige del af befolkningen som helhed havde en rate på 21 selvmord per 100.000. Som det fremgår af Figur 1, var raten højest for midaldrende med demens.

Vi fandt en forh øjet risiko for at begå selvmord blandt demente (se Tabel 1). Blandt personer fyldt 50-69 år var risikoen for at $\mathrm{d} \phi$ af selvmord over 8 gange højere for mænd med demens end for jævnaldrende uden demens [RR: 8,5; CI-95\%:6,3-11,3]. For kvinder i samme aldersgruppe var selvmordsrisikoen for demente over 10 gange højere end niveauet for dem uden demens [RR:
Figur 1. Selvmordsraten blandt personer fyldt 50 år og derover i Danmark, 1990-2000, i forhold til demensdiagnose.

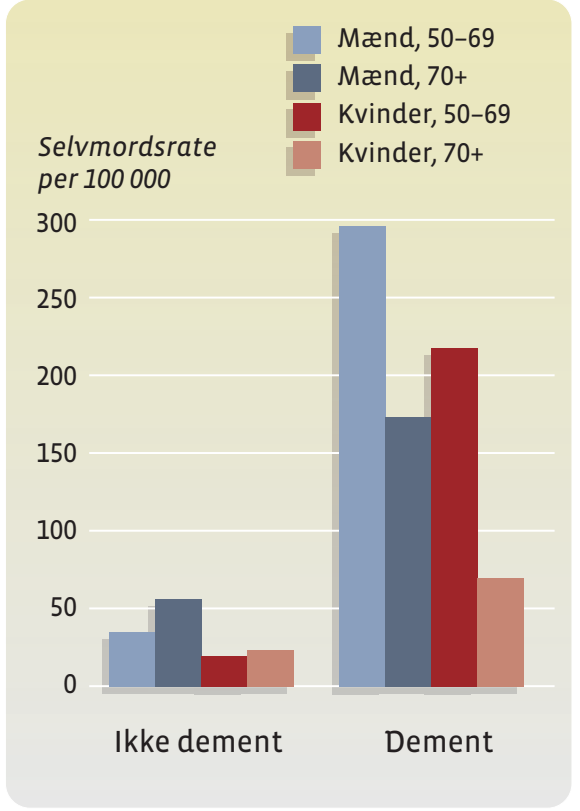

10,8; CI-95\%: 7,4-15,7]. Blandt ældre fyldt 70 år og derover var risikoen for selvmord tre gange højere end referencepopulationen både for mænd og kvinder.

\section{Tidspunkt efter forste diagnose af demens}

Mange selvmord fandt sted relativt kort tid efter første diagnosticeringen af demens. Blandt mænd forekom $40 \%$ af selvmord i de første 12 måneder efter første hospitalsdiagnose med demens. Blandt kvinder var det 38\% af selvmordene, der fandt sted i det første år efter diagnosetidspunktet. Detaljerede analyser viste at risikoen for selvmord var over 13 gange højere i de 6 måneder efter f $\varnothing$ rste hospitalsdiagnose end for personer uden demens (se Figur 2).

Dette var gældende for både mænd [RR: 13,5; CI-95\%: 9,1-20,2] og kvinder

[RR: 13,7; CI-95\%: 8,5-22,1].

Ved hjælp af historiske oplysninger, kunne vi inkludere hospitalsdiagnoser af demens stillet op til 18 år før observationsperioden blev indledt. Henholdsvis $38 \%$ og $42 \%$ af de selvmord som fandt sted blandt mænd og kvinder med demens forekom over 3 år efter første hospitalsdiagnose dvs. relativt sent $\mathrm{i}$ sygdomsforl øbet. 
Tabel 1. Relativ risiko for selvmord for personer fyldt 50 år og derover i Danmark diagnosticeret med demens, 1990-2000. Referencegruppe (sammenligningsgruppe) er markeret med fed typografi. De to sidste modeller, der præsenteres i tabellen, er justeret for kalenderår, alder, ægteskabelig status, samboende status og somatisk comorbiditet.

\begin{tabular}{|c|c|c|c|c|c|c|c|c|}
\hline & \multicolumn{4}{|c|}{ Mænd } & \multicolumn{4}{|c|}{ Kvinder } \\
\hline & $\begin{array}{l}\text { Relativ } \\
\text { risiko }\end{array}$ & $\mathrm{Cl}-95 \%$ & (N) & $\%$ & $\begin{array}{l}\text { Relativ } \\
\text { risiko }\end{array}$ & $\mathrm{Cl}-95 \%$ & (N) & $\%$ \\
\hline \multicolumn{9}{|l|}{ Alder } \\
\hline \multicolumn{9}{|l|}{ Ingen demens } \\
\hline $50-69$ & 1,0 & & 2111 & 59,3 & 1,0 & & 1227 & 57,3 \\
\hline $70+$ & 1,5 & {$[1,4-1,6]$} & 1366 & 38,4 & 1,1 & {$[1,0-1,2]$} & 859 & 40,1 \\
\hline \multicolumn{9}{|l|}{ Demens } \\
\hline $50-69$ & 8,5 & {$[6,3-11,3]$} & 47 & 1,3 & 10,8 & {$[7,4-15,7]$} & 28 & 1,3 \\
\hline $70+$ & 4,7 & {$[3,4-6,7]$} & 33 & 0,9 & 3,4 & {$[2,4-5,0]$} & 28 & 1,3 \\
\hline \multicolumn{9}{|l|}{$\begin{array}{l}\text { Tid siden første } \\
\text { diagnosticering } \\
\text { af demens }\end{array}$} \\
\hline Ingen demens & 1,0 & & 3477 & 97,8 & 1,0 & & 2086 & 97,4 \\
\hline \multicolumn{9}{|l|}{$\begin{array}{l}\text { Demens } \\
\text { diagnosticered: }\end{array}$} \\
\hline < 6 måneder & 13,5 & {$[9,1-20,2]$} & 24 & 0,7 & 13,7 & {$[8,5-22,1]$} & 13 & 0,6 \\
\hline 6 måneder-5 år & 2,8 & {$[2,0-3,9]$} & 33 & 0,9 & 3,2 & {$[2,1-4,9]$} & 26 & 1,2 \\
\hline$>5 \mathrm{ar}$ & 3,0 & {$[2,0-4,5]$} & 23 & 0,6 & 4,9 & {$[2,9-8,1]$} & 17 & 0,8 \\
\hline \multicolumn{9}{|l|}{$\begin{array}{l}\text { Depression som } \\
\text { comorbiditet }+\end{array}$} \\
\hline \multicolumn{9}{|l|}{ Ingen demens } \\
\hline $\begin{array}{l}\text { Ingen } \\
\text { depression }\end{array}$ & 1,0 & & 3134 & 88,1 & 1,0 & & 1660 & 77,5 \\
\hline Depression & 14,4 & {$[12,9-16,1]$} & 343 & 9.6 & 18,8 & {$[16,9-20,9]$} & 426 & 19.9 \\
\hline \multicolumn{9}{|l|}{ Demens } \\
\hline $\begin{array}{l}\text { Ingen } \\
\text { depression }\end{array}$ & 2,8 & {$[2,0-3,8]$} & 39 & 1,1 & 3,3 & {$[2,2-4,8]$} & 27 & 1,3 \\
\hline Depression & 10,8 & {$[8,0-14,7]$} & 41 & 1,2 & 12,2 & {$[8,5-17,7]$} & 29 & 1,4 \\
\hline Total & & & 3557 & 100,0 & & & 2147 & 100,0 \\
\hline
\end{tabular}

\section{Demens og depression}

Personer med dobbeltdiagnoser i form af demens og depression havde en højere selvmordsrisiko end personer udelukkende diagnosticeret med demens (Figur 3). For mænd med demens og ingen depressionsdiagnose var den relative selvmordsrisiko 2.8 [CI-95\%: 2.0-3.8] mens risikoen for dem som havde både demens og depressions diagnoser var 10.8 [CI-95\%: 8.0-14.7], dvs. næsten fire gange højere. For kvinder, var de respektive værdier henholdsvis 3.3 [CI95\%: 2.2-4.8] og 12.2 [CI-95\%: 8.517.7]; dvs. også næsten fire gange høj-
Figur 2. Relativ selvmordsrisiko for personer uden demens (risiko=1), diagnosticeret med demens inden for seneste 6 måneder, inden for 6 måneder- 5 år, mere end 5 år siden for personer fyldt 50 år og derover i Danmark, 1990-2000. Modellen er justeret for kalenderår, alder, ægteskabelig status, samboende status, og somatisk comorbiditet.

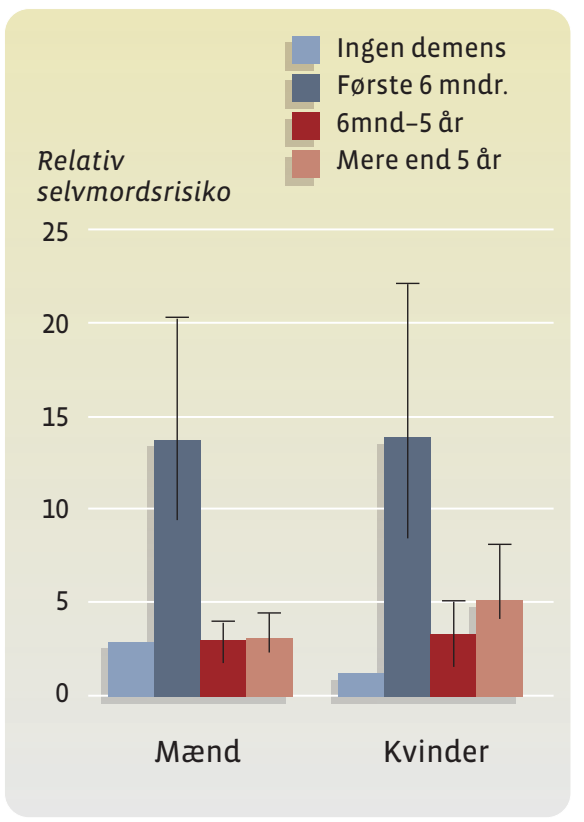

Figur 3. Relativ selvmordsrisiko for personer uden demens (risiko=1), kun med demens og med både demens samt depression for personer fyldt 50 år og derover i Danmark, 1990-2000. Modellen er justeret for kalenderår, alder, ægteskabelig status, samboende status, og somatisk comorbiditet.

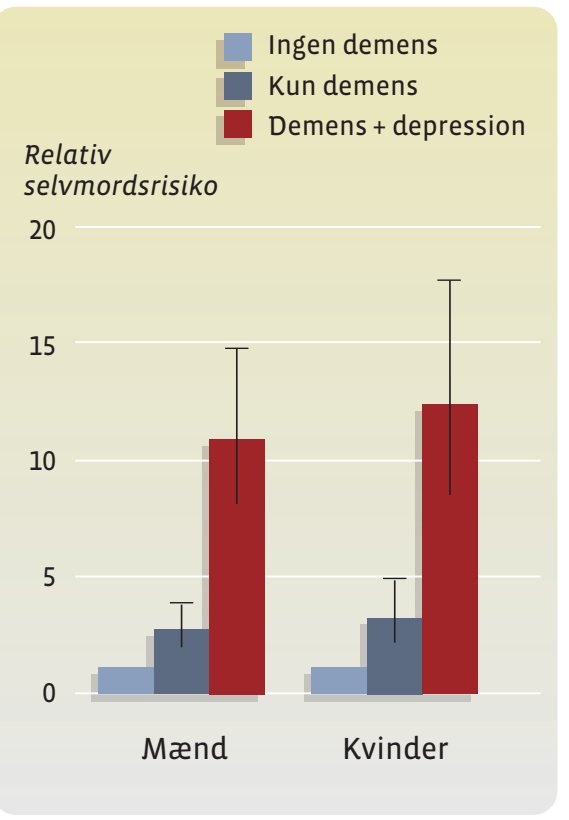


risiko for selvmord. Selvom personer der var diagnosticeret med både demens og depression havde en højere selvmordsrisiko, var der også en forhøjet selvmordsdødelighed blandt personer der udelukkende var diagnosticeret med demens.

\section{Omfang af problemet}

Antallet af selvmord bland personer med demens svarer til 2-3\% af alle selvmord blandt personer fyldt 50 år og derover. Det er således relativt få af de ældres selvmord som kan tilskrives demens. Man bør dog tage højde for at dette studie kun inkluderer demenspatienter, som er blevet diagnosticeret på et somatisk eller psykiatrisk hospital. Det er muligt at en vis proportion af personer med demens udelukkende bliver diagnosticeret og behandlet af praktiserende læger og således ikke er registreret med en hospitalsdiagnose af demens. Vi har desværre ingen informationer om diagnoser eller sygdomme behandlet hos praktiserende læge. Det absolutte antal af selvmord som beskrives her, kan derfor muligvis betragtes som minimumsværdier.

Fra et demografisk perspektiv er det væsentligt at påpege at antallet af ældste ældre forventes at stige kraftig i de kommende årtier. Hermed forventes også flere demente. Det er således sandsynligt at problemet bliver mere omfangsrigt i kommende årtier.

Et ud af tre selvmord fandt sted over tre år efter første diagnose blev stillet. Resultaterne fra analyserne tyder på at selvmord også finder sted i sygdommens fremskredne stadier. Umiddelbart st $\varnothing t t e r$ dette ikke hypotesen om at begrænsede kognitive færdigheder virker forebyggende overfor selvmord blandt personer med demens.

\section{Stressende hoendelse}

Selvom det absolutte antal er lavt, viser selvmordsraten og de relative risici at især de midaldrende mellem 50-65 år med demens har en meget højere sandsynlighed for at begå selvmord sammenlignet med jævnaldrende uden demens. En mulig årsag til dette er at sygdommen rammer i et livsstadie, hvor man sædvanligvis ikke forventer at få demens.
Det kan være mere stressende for en patient at blive konfronteret med en demensdiagnose i en relativ ung alder; en 54-årig med demens står mere isoleret og i kontrast til personens vante omgivelser end en 83-årige med demens. Sygdommen er for en yngre person måske mere uventet. Det er desuden muligt at yngre personer har større indsigt i sygdommens udvikling og udgang.

Udsigten til som dement at miste kontrollen over sit eget liv og blive afhængig af hjælp kan ligeledes være vigtige elementer i beslutningen om at begå selvmord (Kjolseth, 2010).

\section{Sammenhaeng mellem demens og depression}

Personer, som var diagnosticeret med både demens og depression, havde en signifikant højere selvmordsrisiko end dem som udelukkende havde en demensdiagnose. Depression er forbundet med en højere sandsynlighed for selvmord blandt ældre (Conwell \& Thompson, 2008). Studier har tillige påvist en sammenhæng mellem optræden af demens og depression (Nilsson et al., 2002).

Hypotetisk var det muligt at den højere selvmordsrisiko hos demente kunne forklares med den hyppigere forekomst af depression i denne persongruppe. Vore analyser peger dog på at den højere selvmordsrisiko blandt personer med demens tilsyneladende ikke udelukkende skyldes depressiv comorbiditet. Når der i de statistiske analyser blev justeret for hospitalsdiagnoser af depression, fandt vi at personer med demens bibeholdte en signifikant højere selvmordsrisiko sammenlignet med personer uden demens.

\section{Forebyggelse}

Vore detaljerede analyser viste at en stor del af selvmordene finder sted i tiden efter første hospitalsdiagnose. På grund at databegrænsninger var det ikke muligt at unders $\varnothing$ ge om en lignende ophobning af selvmord finder sted blandt de personer med demens som udelukkende unders $\varnothing$ ges hos praktiserende læge. Vores fund understreger at tiden umiddelbart efter første diagnose er et oplagt tidspunkt at iværksættelse forebyggelse.
Det er muligt at bedre opfølgning, screening for depression, øget dækning af informationsbehov kan forebygge selvmord hos demente (Erlangsen et al., 2011).

Kun få studier har dokumenteret en forebyggende effekt overfor ældres selvmord (Lapierre et al., 2011). Forebyggende initiativer rettet mod en relativ lille, befolkningsgruppe med en $\varnothing$ get risiko for selvmord viser lovende resultater bl.a. opfølgning med case managers blandt deprimerede ældre (Alexopoulos et al., 2009; Unutzer et al., 2006) samt opfølgning og udrustning med en alarmfunktion overfor ældre i risikogrupper (De Leo et al., 2002). Lignende initiativer kunne tænkes overfor demente ældre med højere risiko for selvmord.

\section{Hovedpunkter:}

- Eldre diagnosticeret med demens har en højere selvmordsrate end jævnaldrende i den generelle befolkning.

- Tiden kort efter første demensdiagnose er forbundet med en højere selvmordsrisiko.

- Personer med dobbeltdiagnoser (demens og depression) har højere risiko for selvmord end personer som udelukkende er diagnosticeret med demens.

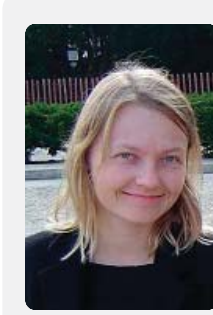

Annette Erlangsen er ansatt som seniorforsker ved Psykiatrisk Center København samt som adjunct assistant professor ved Department of Mental Health, Johns Hopkins School of Public Health, Baltimore, USA. Hun har siden sitt Ph.D.-prosjekt i hovedsak vært opptatt med registeranalyser av prediktorer for selvmord hos eldre. Resultatene fra disse studiene er offentliggjort i en rekke internationale tidsskrifter. I tillegg er Annette Erlangsen aktivt medlem av Forskergruppen Aldre og Selvmord $i$ Danmark samt kontaktperson for International Research Group on Suicide among the Elderly. 


\section{Referanser}

Alexopoulos, G. S., Reynolds, C. F., III, Bruce, M. L., Katz, I. R., Raue, P. J., Mulsant, B. H. et al. (2009). Reducing Suicidal Ideation and Depression in Older Primary Care Patients: 24-Month Outcomes of the PROSPECT Study. Am J Psychiatry, 166, 882-90.

Conwell, Y. (1995). Dementia. Crisis, 16, 5.

Conwell, Y. \& Thompson, C. (2008). Suicidal behavior in elders. Psychiatr Clin North Am, 31, 333-56.

De Leo, D., Buono, M. D., \& Dwyer, J. (2002). Suicide among the elderly: the long-term impact of a telephone support and assessment intervention in northern Italy. Br J Psychiatry, 181, 226-9.

Erlangsen, A., Bille-Brahe, U., \& Jeune, B. (2003). Differences in suicide between the old and the oldest old. The Journals of Gerontology: Psychological Sciences and Social Sciences, 58B, 314-22.

Erlangsen, A., Nordentoft, M., Conwell, Y., Waern, M., De Leo, D., Lindner, R. et al. (2011).
Key considerations for preventing suicide in older adults: Consensus opinions of an expert panel. Crisis, 32, 106-9.

Erlangsen, A., Zarit SH, \& Conwell, Y. (2008). Hospital-diagnosed dementia and suicide: A longitudinal study using prospective, nationwide register data. Am J Geriatr Psychiatry, 16, 220-8.

Erlangsen, A., Zarit, S. H., Tu, X., \& Conwell, Y. (2006). Suicide among older psychiatric inpatients: An evidence-based study if a highrisk group. American Journal of Geriatric Psychiatry, 14, 734-41.

Ferri, C. P., Prince, M., Brayne, C., Brodaty, H., Fratiglioni, L., Ganguli, M. et al. (2005). Global prevalence of dementia: a Delphi consensus study. Lancet, 366, 2112-7.

Harris, E. C. \& Barraclough, B. (1997). Suicide as an outcome for mental disorders. A metaanalysis. Br J Psychiatry, 170, 205-28.

Kjolseth, I. (2010). Control in life and death: an understanding of suicide among the elderly. Department of Behavioural Sciences in Medicine, Institute of Basic Medical Sciences, Faculty of Medicine, University of Oslo, Norway.
Lapierre, S., Erlangsen, A., Waern, M., De, L. D., Oyama, H., Scocco, P. et al. (2011). A systematic review of elderly suicide prevention programs. Crisis, 32, 88-98.

Mosbech, J., Jørgensen, J., Madsen, M., Rostgaard, K., Thornberg, K., \& Poulsen, T. D. (1995). Landspatientregisteret. Ugeskr Laeger, 157, 3741-5.

Munk-Jørgensen, P. \& Mortensen, P. B. (1997). The Danish Psychiatric Central Register. Dan Med Bull, 44, 82-4.

Nilsson, F. M., Kessing, L. V., Sørensen, T. M., Andersen, P. K., \& Bolwig, T. G. (2002).

Enduring increased risk of developing depression and mania in patients with dementia. J Neurol Neurosurg Psychiatry, 73, 40-4.

Paykel, E. S. (1976). Life stress, depression and attempted suicide. J.Human Stress., 2, 3-12.

Unutzer, J., Tang, L., Oishi, S., Katon, W., Williams, J. W., Jr., Hunkeler, E. et al. (2006). Reducing suicidal ideation in depressed older primary care patients. J Am Geriatr Soc, 54, 1550-6.

\section{Erratum}

\section{Forekomst, forløp og risikofaktorer ved selvskade hos norske skoleungdommer - funn fra "Ungdom og psykisk helse"}

Artikkelen er ved Anne Mari Sund og Bo Larsson og ble publisert i Suicidologi nr. 1/2011. Redaksjonen beklager at det oppstod enkelte feil i tabell $1 \mathrm{og}$ i avsnittet "Risikofaktorer og selvskadende atferd - ujusterte analyser". Feilene er rettet opp, og vi gjengir korrigert tabell og kapittel her. Artikkelen i sin helhet er gjengitt på NSSFs nettsider, www.selvmord.no

Tabell 1

Signifikante forskjeller ( $p<0.05)$ mellom ungdom som ikke rapporterer om selvskade og ungdom med selvskading med og uten suicidal hensikt blant 2464 ungdommer i Midt- Norge målt på T1 (13.7 år).

\begin{tabular}{|c|c|c|c|}
\hline Prediktor & $\begin{array}{c}\text { Ungdommer } \\
\text { uten selv- } \\
\text { skading N=2,267 }\end{array}$ & $\begin{array}{c}\text { Selvskading } \\
\text { uten suicidal } \\
\text { hensikt N=71 }\end{array}$ & $\begin{array}{c}\text { Selvskading } \\
\text { med suicidal } \\
\text { hensikt N=71 }\end{array}$ \\
\hline $\begin{array}{c}\text { "Humøret Ditt”a } \\
\text { Livet er ikke verd å leve }\end{array}$ & $1,5 \%$ & $5,6 \%$ & $39,4 \%{ }^{\mathrm{b}}$ \\
\hline $\begin{array}{c}\text { Tanker på døden eller på å dø } \\
\text { Tanker om å ta livet mitt }\end{array}$ & $2,5 \%$ & $9,9 \%$ & $40,8 \%^{\mathrm{b}}$ \\
\hline $\begin{array}{c}\text { Kjenne noen som har prøvd } \\
\text { a ta /tatt livet sitt }\end{array}$ & $0,9 \%$ & $1,4 \%$ & $31,0 \%{ }^{\mathrm{b}}$ \\
\hline I familien & $30,6 \%$ & $52,2 \%$ & $61,3 \%$ \\
\hline En venn & $3,7 \%$ & $10,0 \%$ & $12,1 \%$ \\
\hline Annen person & $11,1 \%$ & $23,0 \%$ & $39,4 \%{ }^{\mathrm{b}} \%$ \\
\hline
\end{tabular}

Noter: a = "Humøret Ditt"-spørsmål skåret som "Riktig” (siste 2 uker)

$\mathrm{b}=$ Andelen ungdommer som skader seg selv med suicidal hensikt høyere enn ungdommer uten suicidal hensikt i Kji-kvadrat-analyser

\section{Risikofaktorer og selvskadende atferd - ujusterte analyser}

I de ujusterte logistiske regresjonsanalysene ble mulige risikofaktorer undersøkt hver for seg. I forhold til risiko for nye (insidente) tilfeller av selvskading fra T1 til T2 ble det påvist store forskjeller med hensyn til psykososiale risikofaktorer mellom ungdommer som skadet seg selv og ungdommer som ikke skadet seg selv. Ungdommer med høyest risiko for selvskading var mer belastet på mange områder, både i familien, på skolen, i fritiden og helsemessig (Larsson \& Sund, 2008). De ujusterte analysene viste også forskjell på ungdommer som skader seg selv med og uten suicidal hensikt: Ungdommer med suicidal hensikt rapporterte på T1 mye høyere nivå av depressive symptomer og selvmordstanker og scoret høyere når det gjaldt internaliserende og eksternaliserende (atferds-)problemer målt på YSR enn ungdom uten suicidal hensikt. De kjente også langt oftere en venn som hadde gjort selvmordsfors $\varnothing \mathrm{k} /$ tatt livet sitt $(39,4 \%$ versus $23 \%$ ). 